\title{
Environmental factors affecting malaria parasite prevalence in rural Bolifamba, South- West Cameroon
}

\author{
Theresa Nkuo-Akenji *, Nelson N. Ntonifor, Maze B. Ndukum, Helen K. Kimbi , Edith L. Abongwa, \\ Armand Nkwescheu, Damain N. Anong, Michael Songmbe, Michael G. Boyo, Kenneth N. \\ Ndamukong and Vincent P.K. Titanji \\ Faculty of Science, Department of Life Sciences, University of Buea, P.O. Box 63, Buea, South West \\ Province, Cameroon \\ *Corresponding author; Email: WIFON@,YAHOO.COM
}

\begin{abstract}
SUMMARY
The impact of some environmental factors on malaria parasite prevalence was investigated in rural Bolifamba, Cameroon. The study population comprised 1454 subjects aged 0 - 65 years. Malaria parasite prevalence was higher in the rainy $(50.1 \%)$ than in the dry season $(\mathbf{4 4 . 2 \% )}$ ) with a significant difference $(P=\mathbf{0 . 0 0 1})$ in mean parasite density between seasons. Individuals $<15$ years old, had significantly higher malaria parasite prevalence $(55.5 \%)$ than those $>15$ years $(37.4 \%)$. Malaria parasite prevalence $(\mathrm{P}=\mathbf{0 . 0 0 1})$ and parasite density $(\mathrm{P}=\mathbf{0 . 0 3})$ were higher in the individuals of wooden plank houses than those of cement brick houses. Inhabitants of houses surrounded by bushes or garbage heaps and swamps or stagnant water showed higher malaria parasite prevalence and densities compared with those from cleaner surroundings. Anopheles gambiae $(63.8 \%)$ and $A$. funestus $(32.8 \%)$ were associated with perennial transmission of malaria. Our data indicates that poor environmental sanitation and housing conditions may be significant risk factors for malaria parasite burden in Bolifamba.
\end{abstract}

[Afr J Health Sci. 2006; 13:40-46]

\section{Introduction}

Malaria is prevalent throughout Cameroon with transmission being affected by climate and geography [1,2], increased drug resistance and the lack of adequate vector control measures [3]. Reduction in man-vector contact may be achieved by the use of protective clothing, insect repellents, bed nets, insecticides or environmental management. In Zambia, multiple control interventions, including environmental management against Anopheles larval stages and improvement in hygiene and sanitation reduced the overall malaria incidence and mortality rates by approximately 50\% [4]. In Europe and North America, malaria was eliminated through use of insecticides and manipulation of the environment [5]. Preliminary studies in Bolifamba indicate that malaria transmission is perennial [6] with Anopheles mosquitoes occurring throughout the year. Factors favouring mosquitoes may include the bushes, garbage heaps, swamps and stagnant pools of water that surround many houses in the village. The poor housing conditions may also encourage man-vector contact.

The study reported here therefore had as the objective to investigate the effect of entomological and environmental factors on malaria parasite prevalence and parasite density and provide information that could be used by the public health sector for improving its malaria control strategy.

\section{Materials and Methods}

\section{Study site}

Bolifamba is a village in South West Cameroon at $247.89^{\circ} \mathrm{N}$ and $58.24^{\circ} \mathrm{E}$ and an altitude of 530 on the east slope of Mount Cameroon, $25 \mathrm{~km}$ from the Atlantic Ocean. 


\section{RESEARCH ARTICLE}

It has a relative humidity of $80 \%$, a temperature range of $18^{\circ} \mathrm{C}-23^{\circ} \mathrm{C}$ and an annual rainfall of $4090 \mathrm{~mm}$. It has an equatorial climate with a rainy season from March to October and a dry season from November to February but the rainfall pattern is changing with rains beginning in June. A slow flowing permanent stream flows across the village. A low-lying marshy area that permits the persistence of anopheline breeding year round bound the village on the Southwestern side. The inhabitants are of several ethnic groups and the main occupation is farming. There are two main house types - cement brick and plank (wood) houses.

\section{Parasitological studies}

For malaria prevalence studies, 1454 subjects of both sexes aged $0-65$ years were selected at random. Informed consent was obtained from the parents and guardians of all minors. In August 2002 (the peak transmission period), 208 children aged $0-14$ years were selected to assess the impact of housing and environmental conditions on malaria prevalence and parasite density. Ethical clearance was obtained from the Provincial Delegation of Public Health. Thick smears were prepared, stained with Giemsa solution and observed under 100X objective. Slides were reported negative for parasites only after observing at least 50 fields. Parasite density was determined by counting the number of malaria parasites against 200 white blood cells and expressing the resultant number of parasites $/ \mu$ l blood assuming a white blood cell count of 8000 per $\mu 1$ of blood [7].

\section{Entomology}

Mosquitoes were collected by human landing catches and spray catch in the dry and rainy seasons. Eight adult volunteers served as mosquito collectors as well as human baits, half caught mosquitoes using aspirators in two 6 hourly shifts from $6 \mathrm{pm}$ to 6 am from 8 houses each month. Spray catches were done in 4 rooms per sector in 4 sectors of the village every month. Rooms were sprayed with a pyrethrum-based insecticide. Ten minutes after spraying, adult mosquitoes were collected from floor sheets. Adult Anophelines were identified using the Gilles and de Meillon morphologic identification keys. Human biting rate (HBR) per person per night was calculated from the human landing catches and the hourly night biting pattern determined. Rainfall data for the Bolifamba area was obtained from the Cameroon Tea Estate.

\section{Statistical analysis}

All parasitological and entomological data was analyzed with the statistical package for social sciences (SPSS) [8]. Proportions were compared using the chi-square or t-test. Means were compared using analyses of variance (ANOVA) while significant levels were measured at $95 \%$ confidence level with significant differences recorded at $\mathrm{p}<0.05$.

\section{Results}

\section{Malaria prevalence and parasite density}

Six hundred and forty one males and 813 females aged $0-65$ years were examined. No significant difference $(\mathrm{p}=0.75)$ in the prevalence of malaria parasite was observed between males $(46.1 \%)$ and females $(47.0 \%)$. Malaria parasite was prevalent throughout the year but was significantly higher in the rainy season $[50.1 \%(284 / 567)]$ than in the dry season $[44.2 \%(392 / 887)]\left(\chi^{2}=4.8 ; \mathrm{P}=0.028\right)$. Parasite density ranged from $38-50252$ parasites $/ \mu 1$ blood. The geometric mean parasite density was $470 \pm 9318$ and $414 \pm 432$ parasites $/ \mu 1$ blood for the rainy and dry season respectively, and this difference was also significant $(\mathrm{t}=0.86 ; \mathrm{df}=1 ; \mathrm{P}=0.001)$. Malaria parasite prevalence and mean parasite density declined after age 14 (Table 1). Prevalence in children from 0-14 years was $55.5 \%$ and in adults $15-65$ was $37.4 \%$ $(\mathrm{P}<0.05)$. Mean parasite density was higher in subjects aged 0-14 year than in those 15-65 years old (Table 1).

\section{Entomological observations}

A. gambiae and A. funestus were both predominant through out the year but the population of the former was higher during the rainy season while the later was higher in the dry season. Two thousand six hundred and thirty mosquitoes were collected by the human landing catches and 442 by the spray catch technique (Table 2). The biting cycles of all Anopheles species showed peak biting hours between 1-2a.m. and 2-3a.m. irrespective of 
season (Fig 1A \& 1B). Biting rates were higher for A. gambiae than for other species. The rainfall data is shown on Fig. 2 with peak rainfall occurring in the months of July and August. There was more biting during the rainy season than in the dry season

Table 1: Malaria parasite prevalence and geometric mean parasite density (GMPD) by age group.

\begin{tabular}{cccc}
\hline $\begin{array}{c}\text { Age group } \\
\text { (years) }\end{array}$ & $\begin{array}{c}\text { Number } \\
\text { infected }\end{array}$ & $\begin{array}{c}\text { Prevalence } \\
(\%)\end{array}$ & $\begin{array}{c}\text { GMPD } \\
\text { (Parasites/ } \boldsymbol{\mu l} \text { blood } \pm \text { SD) }\end{array}$ \\
\hline $\mathbf{0 - 1}$ & $37(75)^{*}$ & 49.3 & $2915 \pm 8727$ \\
$\mathbf{2 - 5}$ & $173(261)$ & 66.3 & $3469 \pm 12069$ \\
$\mathbf{6 - 9}$ & $96(193)$ & 49.7 & $1437 \pm 5233$ \\
$\mathbf{1 0 - 1 4}$ & $95(190)$ & 50.0 & $1081 \pm 5673$ \\
$\mathbf{1 5 - 6 5}$ & $275(735)$ & 37.4 & $328 \pm 777$ \\
\hline
\end{tabular}

Malaria prevalence: At 95\% confidence level, $\chi^{2}=67.44 ; \mathrm{df}=4 ; \mathrm{P}=0.00$

Mean parasite density $\mathrm{F}=2.94 ; \mathrm{df}=4, \mathrm{P}=0.0006$

*(Total number of individuals tested per age group)

Table 2: Percent Anopheline abundance (n).

\begin{tabular}{lll}
\hline & \multicolumn{2}{c}{ Seasons } \\
\cline { 2 - 3 } Spray catch technique & Rainy season & Dry season \\
A. gambiae & $46.2^{*}$ & 41.4 \\
& $(97)^{* *}$ & $(96)$ \\
A. funestus & 52.4 & 56.0 \\
& $(109)$ & $(130)$ \\
A. hankocki & 1.4 & 2.6 \\
& $(3)$ & $(6)$ \\
Total & 100 & 100 \\
Human landing catch & $(209)$ & $(2320$ \\
technique & & \\
A. gambiae & 66.8 & 44.5 \\
A. funestus & $(584)$ & $(66.2)$ \\
& 32.4 & 50.3 \\
A. hankocki & $(283)$ & $(747)$ \\
& 0.8 & 5.2 \\
Total & $(7)$ & $(77)$ \\
* & 100 & $(1486)$ \\
** Percentage of mosquitoes caught) & & \\
(Numbers caught) & &
\end{tabular}

Of the 117 houses examined, $31(26.5 \%)$ were built with cement bricks and $86(73.5 \%)$ with wooden plank. The average number of occupants per house was 7. Ceilings were present in $20.5 \%$ cement brick and $11.9 \%$ wooden plank houses. However, the presence of a ceiling did not have any influence on parasite density. The malaria parasite prevalence for children living in wooden plank and cement brick houses was $62.7 \%$ and $45.4 \%$ respectively and the difference was significant $\left(\chi^{2}=13.56 ; \mathrm{P}=0.00\right)$. The geometric 


\section{RESEARCH ARTICLE}

mean parasite density was $5117 \pm 6682$ and $3550 \pm 4622 / \mu 1$ blood for children living in wooden plank and cement brick houses respectively $\left(\chi^{2}=9.5 ; \mathrm{P}=0.025\right)$. Children living in houses in which bed nets were not used had higher malaria parasite prevalence than those who used bed nets $(67.5 \%$ versus $45.5 \% ; \chi^{2}=5.57 ; \mathrm{P}=0.02$ ).

\section{Effect of environmental conditions on malaria parasite}

Malaria parasite prevalence and parasite density was higher in children living in houses surrounded by bushes/garbage and swamps/stagnant pools of water (Tables 3 and 4 respectively) when compared with those inhabiting cleaner environments. There was a high positive correlation between swamps and stagnant pools and malaria parasite prevalence $(\mathrm{r}=0.82 ; \mathrm{P}=0.001)$ while bushes and garbage were not highly positively correlated $(\mathrm{r}=0.56$; $\mathrm{P}=0.001)$.

Fig. 1. Anopheles species peak biting hours in the rainy (A) and in the dry (B) seasons

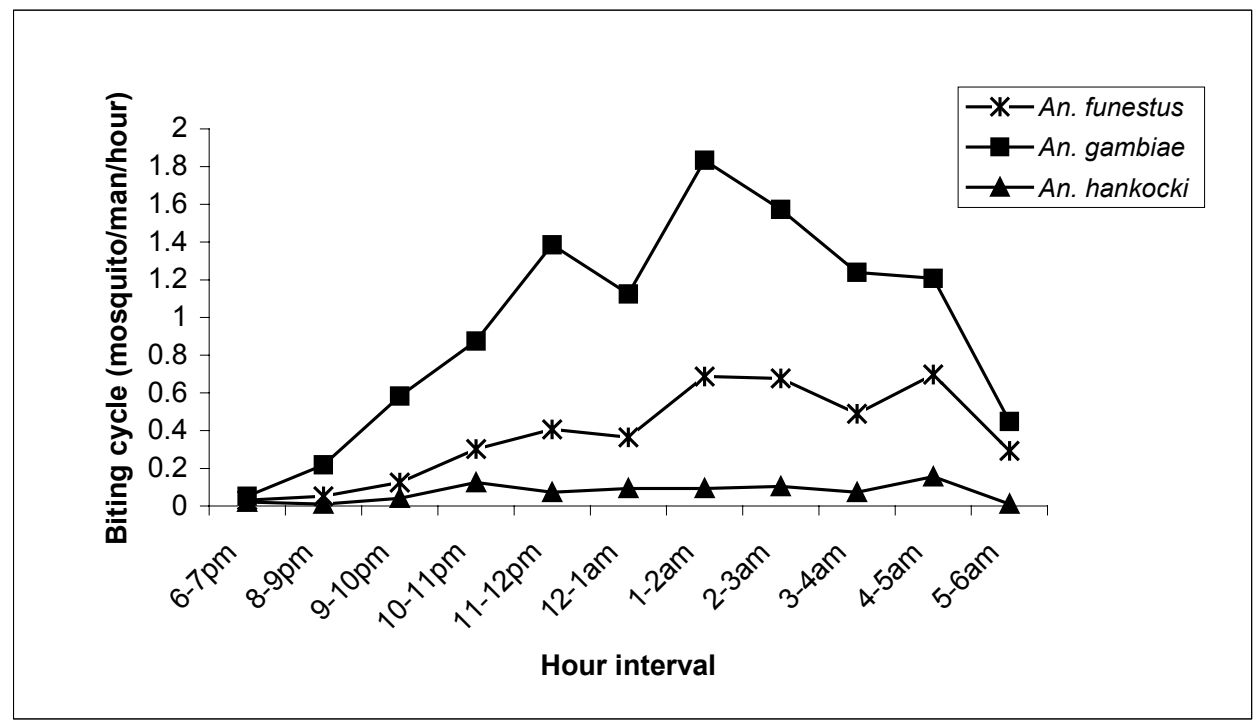

A

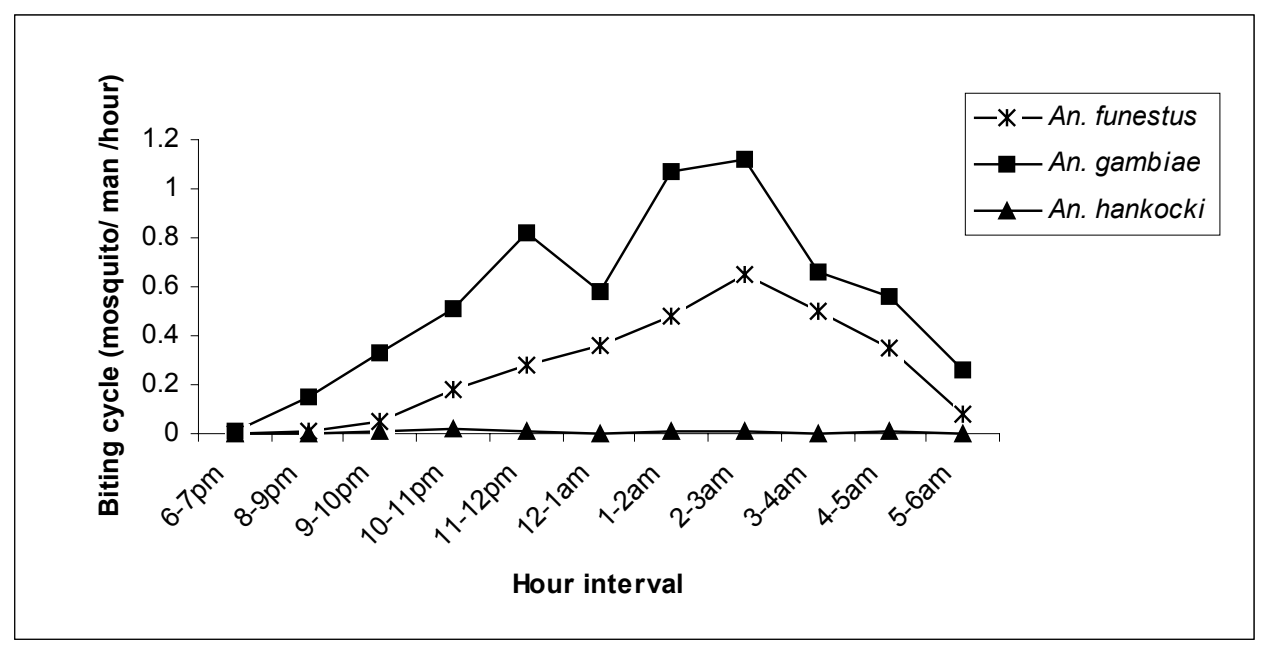


RESEARCH ARTICLE

Table 3: Association of environmental factors with malaria parasite prevalence.

\begin{tabular}{llllll}
\hline Environmental Factor & ${ }^{1}$ Present & ${ }^{2}$ Absent & $\chi^{2}$ & d.f. & P \\
& & & & & \\
\hline $\begin{array}{l}\text { Bushes/garbage } \\
\text { Swamps/Stagnant pools } \\
\text { of water }\end{array}$ & ${ }^{*} 69.7 \%(69 / 99)$ & $47.7 \%(52 / 109)$ & 10.31 & 3 & 0.00 \\
$\begin{array}{l}\text { Bushes/garbage and } \\
\text { swamps/Stagnant pools } \\
\text { of water }\end{array}$ & $60.5 \%(26 / 43)$ & $35.0 \%(7 / 20)$ & 6.0 & 3 & 0.04 \\
$\begin{array}{l}{ }^{1} \text { Presence of environmental condition } \\
{ }^{2} \text { Absence of environmental condition }\end{array}$ & $48.4 \%(60 / 124)$ & 12.09 & 3 & 0.00 \\
${ }^{*}$ Malaria prevalence & & & & & \\
\end{tabular}

Table 4: Association of environmental factors with parasite density

\begin{tabular}{|c|c|c|c|c|c|c|}
\hline \multirow{2}{*}{$\begin{array}{c}\text { Parasite } \\
\text { density }\end{array}$} & \multicolumn{2}{|c|}{$\begin{array}{c}\text { Swamps/stagnant pools of } \\
\text { water }\end{array}$} & \multicolumn{2}{|c|}{ Bushes/garbage } & \multicolumn{2}{|c|}{$\begin{array}{c}\text { Swamps/ stagnant pools } \\
\text { of water and } \\
\text { bushes/garbage }\end{array}$} \\
\hline & Present & Absent & Present & Absent & Present & Absent \\
\hline$>10.000$ & $28 *(45.9 \%)$ & $10(16.7 \%)$ & $20(29.0 \%)$ & $18(34.6 \%)$ & $10(38.5 \%)$ & $0(0.0 \%)$ \\
\hline$>1000$ & $2(3.3 \%)$ & $13(21.7 \%)$ & $8(11.6 \%)$ & $7(13.5 \%)$ & $6(23.1 \%)$ & $3(42.9 \%)$ \\
\hline$>400$ & $12(19.7 \%)$ & $27(45.5 \%)$ & $30(43.5 \%)$ & $9(17.3 \%)$ & $7(26.9 \%)$ & $2(28.6 \%)$ \\
\hline $1-399$ & $19(31.1 \%)$ & $10(16.7 \%)$ & $11(15.9 \%)$ & $18(34.6 \%)$ & $3(11.5 \%)$ & $2(28.6 \%)$ \\
\hline Total & 61 & 60 & 69 & 52 & 26 & 7 \\
\hline$\chi^{2}$ & 25.14 & & 10.99 & & 5.0 & \\
\hline d.f. & 3 & & 3 & & 3 & \\
\hline $\mathrm{P}$ & 0.001 & & 0.012 & & 0.015 & \\
\hline
\end{tabular}

${ }^{*}$ Number of positive cases

\section{Relationship between anopheles species abundance with malaria}

A high Anopheles species population corresponded with higher malaria parasite prevalence and parasite density. A positive correlation was recorded between total Anopheles population and malaria parasite prevalence $(\mathrm{r}=0.50 ; \mathrm{P}=0.001)$ as well as mean parasite density $(\mathrm{r}=0.51 ; \mathrm{P}=0.001)$.

\section{Discussion}

Malaria parasite prevalence differed between age groups with the highest prevalence in children less than 15 years old (55.5\%). Lower mean parasite densities were recorded in adults than in children. This accord with similar studies conducted in Bamenda, Douala and Yaounde, [9] and has been attributed to protective immunity as a result of previous exposure to malaria.

Entomological surveys conducted in our study revealed that $A$. funestus and $A$. gambiae were the predominant Anopheles species and malaria transmission vectors in Bolifamba. In many areas of Africa, Anopheles gambiae is found together with an equally important vector A. funestus [10]. A. gambiae accounted for about $68 \%$ of adult human bait catches, in both the rainy and dry seasons. A. funestus was the most populated species caught during 


\section{RESEARCH ARTICLE}

spray catches (done indoors) for both seasons. A low $A$. hankocki population was recorded in this study. This species has been reported to be a secondary vector in malaria transmission and will effect transmission in the presence of the main transmission vectors [11].

The seasonal variation in malaria parasite prevalence in Bolifamba can be attributed to changes in Anopheles abundance during the year. High rainfall in the rainy season (Fig. 2) produced pools and swamps due to poor drainage, producing suitable conditions for mosquitoes. In the dry season, the formation of water pools around some public water taps due to poor drainage, coupled with much sunlight was conducive to breeding of $A$. gambiae $[12,2]$. Thus the persistence of some swamps, together with the existence of bushes or plantains that surround many households which serve as resting sites for these mosquitoes during the dry season leads to high exposure to mosquito bites and risk of malaria parasite infect all year round.

Houses built with plank had breaks and crevices on the walls and ceiling boards that provided refuges and allowed for easy passage of mosquitoes. This may explain why more mosquitoes were caught in plank houses than brick houses and the higher malaria parasite prevalence in children living in plank versus brick houses.

Bed nets were shown to be protective but most of them were old and some torn, which explain why children in houses where bed nets were used still had relatively high malaria prevalence. None of the bed nets were treated with insecticides. The presence of ceiling boards in some houses did not reduce malaria parasite prevalence as the boards did not completely cover the roof or had cracks in them, which served as passage ways for mosquitoes

Figure 2. Mean rainfall data (mm) for 2001 and 2002.

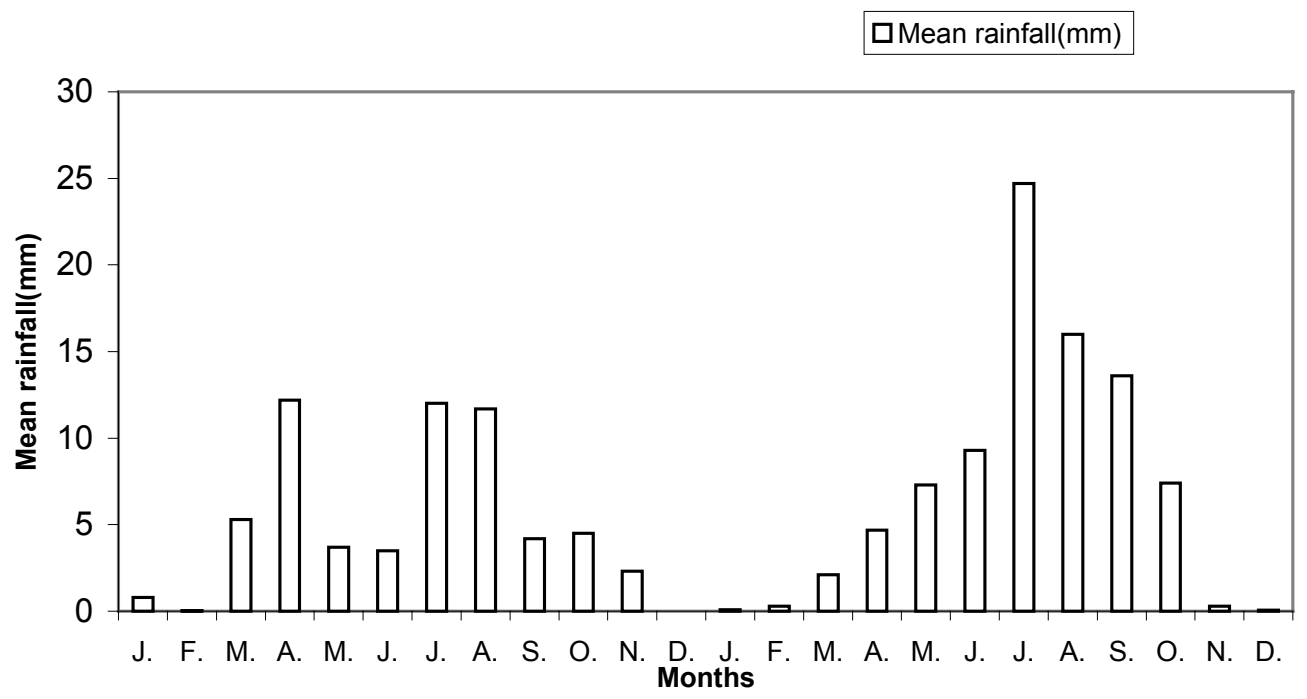

The impact of environmental surroundings on malaria prevalence was potentially important the highest malaria prevalence being recorded in children living in houses surrounded by bushes and swamps. High Anopheles species populations were caught from these environments. A reduction of malaria transmission in this area might be achieved by control interventions involving environmental management alongside the use of bed nets [4]. Implementation of an environmental control programme could be achieved by improving drainage of flooded areas and swamps and through campaigns to clear bushes and disposal of garbage (such as building local incinerators). House improvements should take into consideration the sealing off of crevices and breaks in the walls and roof. 


\section{Acknowledgements}

We thank the University of Buea for providing a malaria research laboratory for our team. Thanks also go to the Chief and the entire population of Bolifamba for participating in the study. This investigation received financial support from UNDP/World Bank/WHO Special Programme for Research and Training in Tropical Diseases.

\section{References}

1. WHO, 1998. Facts Sheets, No. 24:8pp.

2. Fontenille D, Lochouarn L, Diagne N, Sokhna C, Lemasson, J-J, Diatta M, Konate L, Faye F, Rogier C, and Trape JF. High annual and seasonal variations in malaria transmission by Anophelines and vector species composition in Dielmo. A holoendemic area in Senegal. American Journal of Tropical Medicine and Hygiene. 1997; 56: 247-253.

3. Quakyi AI, Leke RG, Befidi-Mengue R, Tsafack M, Bomba-Nkolo D, Manga, L, Tchinda V, Njeugue E, Kouontchou S, Fogako J, Nyonglema P, Harun LT, Djokam R, Sama G, Eno A, Megnekou R, Metenou S, Ndoutse L, Same-Ekobe A, Alake G, Meli J, Ngu J, Tietche F, Lohoue J, Mvondo, J. L, Wansi E, Leke R, Folefack A, Bigoga J, BombaNkolo C, Titanji V, Walker-Abbey A, Hickey AM, Johnson AH, and Taylor, DW. The Epidemiology of Plasmodium falciparum in two Cameroonian villages: Simbok and Etoa. American Journal of Tropical Medicine and Hygiene. 2000; 5: 222-230.

4. Utzinger J, Tozan and Singer BH,. Efficacy and cost effectiveness of environmental management for malaria control. Tropical Medicine and International Health 2001; 6:677 - 687.
5. Shiff C. Integrated approach to malaria control. Clinical Microbiology Review 2002; 15:278-293.

6. Titanji VPK, Tamu VD, Nkuo-Akenji TK, and Joutchop AJ. Immunoglobulin G subclass responses to $P$. falciparum antigens. A study in highly exposed Cameroonians. Clinical and Chemical Laboratory Medicine. 2002; 40:937-943.

7. Earle WC, and Perez M. Enumeration of parasites in the blood of malaria patients. Journal of Laboratory and Clinical Medicine. 1983; 17:1123-1130.

8. Ahorlu KC, Dunyo KS, Afari AE, Koram $\mathrm{AK}$ and Nkrumah KF. Malaria- related beliefs and behaviours in Southern Ghana: implications for treatment, prevention and control. Tropical Medicine and International Health. 1997; 2:488-499.

9. Nkuo-Akenji T, Deas JE, Leke, RG and Ngu JL. Correlation between serum levels of antibodies to the $96 \mathrm{KD}$ antigen of $P$. falciparum and protective immunity in Cameroon: A longitudinal study. American Journal of Tropical Medicine and Hygiene. 1993; 49:566-573.

10. Charlwood JD, Thompson R, and Madsen $\mathrm{H}$. Observations on the swarming and mating behaviour of Anopheles funestus from Southern Mozambique. Malaria Journal.. 2003; 2:2

11. Fontenille D, Wanji S, Djouaka R, Awono - Ambene HP. Anopheles hancocki, vecteur secondaire du paludisme au Cameroun. Bulletin de Liason et de documentation de L'OCEAC. 2000; 3:923.

12. Tadei WP, Thatcher BD, Santos JM, Scarpassa VM, Rodrigues IB and Rafael MS. Ecologocal observations on Anopheline vectors of malaria in the Brazilian Amazon. American Journal of Tropical Medicine and Hygiene. 1998; 59: 325-335. 